\title{
Clinical presentation of patients with aseptic meningitis, factors influencing treatment and hospitalization, and consequences of enterovirus cerebrospinal fluid polymerase chain reaction testing
}

\author{
Glenn Patriquin $\mathrm{MSc}^{1}$, Jill Hatchette $\mathrm{PhD}^{2}$, Kevin Forward $\mathrm{MD}^{1}$
}

G Patriquin, J Hatchette, K Forward. Clinical presentation of patients with aseptic meningitis, factors influencing treatment and hospitalization, and consequences of enterovirus cerebrospinal fluid polymerase chain reaction testing. Can J Infect Dis Med Microbiol 2012;23(1):e1-e5.

INTRODUCTION: Clinical and laboratory features of enteroviral meningitis may overlap with those of bacterial meningitis. In the present retrospective review, we compared features of enteroviral (EV)-positive and-negative patients to determine those that were most influential in admission, discharge and in anti-infective administration.

METHODS: Data were analyzed from the records of 117 pediatric and adult patients who underwent cerebrospinal fluid (CSF) EV testing over a three-year period.

RESULTS: The oldest EV-positive patient was 34 years of age and the occurrence of the disease was highly seasonal. EV-positive patients were more likely to report fever, rash, photophobia, short onset and exposure to an ill contact. A positive polymerase chain reaction (PCR) result was associated with relatively short hospitalization. Seizure and neurological symptoms were more strongly associated with a negative PCR test result. CSF characteristics did not discriminate well between patients with positive and negative PCR tests. Patients with imperfect Glasgow Coma Scores or with neurological symptoms were more likely to be admitted to hospital than those without. Fever and recent onset predicted determinants of anti-infective use.

CONCLUSION: The present retrospective study confirms previous reports regarding seasonality and the young age of positive patients. Factors that indicate nonenteroviral etiology were appropriately also those that influenced hospitalization. Patients with EV meningitis were likely to be treated with empirical anti-infectives, and a substantial proportion continued to take antibiotics for more than $24 \mathrm{~h}$ after receiving the positive EV PCR test result.

Key Words: Aseptic; Cerebrospinal fluid; Diagnostic PCR; Enterovirus; Meningitis

\author{
La présentation clinique de patients ayant une \\ méningite aseptique, les facteurs influant sur le \\ traitement et l'hospitalisation et les conséquences \\ du test de réaction en chaîne de la polymérase \\ dans le liquide céphalorachidien positif aux \\ entérovirus
}

HISTORIQUE : Les caractéristiques cliniques et de laboratoire de la méningite entérovirale peuvent chevaucher celles de la méningite bactérienne. Dans la présente analyse rétrospective, les chercheurs ont comparé les caractéristiques des patients positifs et négatifs à l'entérovirus (EV) pour déterminer celles qui avaient le plus d'influence sur l'admission, le congé et l'administration d'anti-infectieux.

MÉTHODOLOGIE : Les chercheurs ont analysé les données tirées des dossiers de 117 patients pédiatriques et adultes qui avaient subi un test du liquide céphalorachidien (LCR) positif à l'EV sur une période de trois ans. RÉSULTATS : La patiente positive à l'EV la plus âgée avait 34 ans. L'occurrence de la maladie était hautement saisonnière. Les patients positifs à l'EV étaient plus susceptibles de déclarer de la fièvre, des éruptions, de la photophobie, une apparition rapide et une exposition à un contact malade. Les résultats positifs de la réaction en chaîne de la polymérase (PCR) s'associaient à une hospitalisation relativement courte. Les conclusions et les symptômes neurologiques étaient liés plus fortement aux résultats d'un test de PCR négatif. Les caractéristiques du LCR distinguaient mal les patients ayant des tests de PCR positifs de ceux ayant des résultats négatifs. Les patients dont l'indice de coma de Glasgow était imparfait ou qui avaient des symptômes neurologiques étaient plus susceptibles d'être hospitalisés que les autres. La fièvre et une apparition récente étaient prédictives de l'utilisation d'anti-infectieux.

CONCLUSION : La présente étude rétrospective confirme les rapports antérieurs au sujet du caractère saisonnier et du jeune âge des patients positifs. Comme de juste, les facteurs indicateurs d'une étiologie non entérovirale étaient aussi ceux qui influaient sur l'hospitalisation. Les patients ayant une méningite EV étaient susceptibles d'être traités à l'aide d'anti-infectieux empiriques, et une forte proportion d'entre eux continuaient de prendre des antibiotiques pendant plus de 24 heures après avoir reçu le résultat du test PCR positif à EV.

(3). Enterovirsues are of fecal-oral origin and EV meningitis is highly seasonal, usually occurring between the late summer and the fall (2).

A cerebrospinal fluid (CSF) sample is routinely obtained from patients presenting with meningitis and is analyzed for markers of infection. When the Gram stain is negative, the clinician must decide whether there is enough evidence to confidently discount bacterial infection and to discharge the patient.

Identifying the causative agent of meningitis can have a positive impact on patient outcomes, but can also conserve health care resources. Previous work has shown that the care for a patient with meningitis can cost between $\$ 3,300$ and $\$ 18,000$ (3). The 


\begin{tabular}{|c|c|c|c|}
\hline \multirow[b]{2}{*}{ Characteristic } & \multicolumn{2}{|c|}{ EV PCR result } & \multirow[b]{2}{*}{$\mathbf{P}$} \\
\hline & Positive & Negative & \\
\hline Male sex & $34(55.9)$ & $83(51.8)$ & 0.839 \\
\hline Age, years, mean \pm SEM $(n)$ & $7.9 \pm 2.0(34)$ & $30.2 \pm 2.6(83)$ & $<0.001$ \\
\hline Headache & $12(91.7)$ & $62(70.1)$ & 0.169 \\
\hline Fever & $34(70.6)$ & $83(21.7)$ & 0.002 \\
\hline Stiff neck & $1(33.3)$ & $62(29.0)$ & 0.742 \\
\hline Rash & $34(35.3)$ & $83(12.0)$ & 0.008 \\
\hline Photophobia & $12(58.3)$ & $62(21.0)$ & 0.013 \\
\hline$<48$ h onset & $28(78.6)$ & $81(46.9)$ & 0.004 \\
\hline Exposure & $34(26.5)$ & $82(9.8)$ & 0.040 \\
\hline Seizure & $34(2.9)$ & $83(18.1)$ & 0.037 \\
\hline Focal neurological findings & $34(6.3)$ & $83(36.1)$ & 0.001 \\
\hline GCS, mean \pm SEM $(n)$ & $14.7 \pm 0.3(9)$ & $14.3 \pm 0.2(54)$ & 0.476 \\
\hline Nausea/vomiting & $34(38.2)$ & $83(50.6)$ & 0.308 \\
\hline Confusion/LOC & $12(8.3)$ & $62(32.3)$ & 0.160 \\
\hline Temperature, ${ }^{\circ} \mathrm{C}$, mean \pm SEM & $38.0 \pm 0.2$ & $37.2 \pm 0.1(81)$ & $<0.001$ \\
\hline
\end{tabular}

Data presented as $n(\%)$, unless otherwise indicated. GCS Glasgow Coma Score; LOC Loss of consciousness; PCR Polymerase chain reaction

EV polymerase chain reaction (PCR) test is highly sensitive and specific, and more rapid when compared with classical methods of viral isolation $(4,5)$. Because mixed infections are exceedingly uncommon, the identification of EV meningitis using PCR should mandate discontinuation of antibiotics and subsequent discharge, which can reduce hospital costs by up to $35 \%$ (5).

We reviewed the medical records of 117 individuals presenting with signs of meningitis whose CSF was submitted for EV PCR testing. The purpose of the present retrospective study was to establish defining characteristics of EV-positive patients from those suspected of having nonbacterial meningitis, as well as to determine the clinical features that influenced physicians to admit the patient to hospital, institute isolation precautions and to administer anti-infectives. We focused on the EV PCR test of CSF as a diagnostic tool and hypothesized that EV-positive patients would spend less time in hospital and their empirical anti-infective medication would be discontinued if PCR testing was positive.

\section{METHODS}

Subsequent to appropriate ethics approval from both institutions, patients seen at Capital District Health Authority (CDHA) (Halifax, Nova Scotia) hospitals or the Izaak Walton Killam (IWK) Hospital (Halifax, Nova Scotia) whose CSF samples were tested for the presence of enterovirus by means of PCR from January 2006 to December 2008 were identified from the laboratory information systems. All adults from CDHA with either positive or negative EV PCR test results were reviewed. Due to the large volume of pediatric charts, all EV-positive children were reviewed and date-matched to an equal number of EV-negative pediatric patients. For the examination of the seasonality of EV meningitis all 372 Nova Scotian EV PCR-tested patients were included.

Patient charts were reviewed using a standardized data collection tool by a single reviewer (GP). Information collected consisted of demographic factors, clinical characteristics, investigational data and prescribed pharmaceuticals related to the treatment of meningitis (including dates and times of administration). Features typical of meningitis (headache, photophobia, confusion and stiff/painful neck) were collected for those who could reliably report ( $>4$ years of age). For the purposes of the present study, 'focal neurological symptoms' were those that could be attributed to a lesion of the brain or brainstem (gait, speech, motor or sensory deficit, convulsions, balance disturbances and dizziness). Temperatures were those recorded in the emergency department where available, or if not, closest to admission. Only patients whose CSF white blood cell (WBC) count was greater than 9 cells $/ \mathrm{mm}^{3}$ were included in the differential count.

Patients whose isolation (or contact measures) began on the same day as their PCR test result were considered to be isolated after that result. Only patients who were still in isolation for at least two days following the result of the PCR were considered to have remained in isolation post-PCR result. Those who were isolated due to positive methicillin-resistant Staphylococcus aureus (MRSA) results were not used in calculations. Empirical antibiotics included those given for meningitis before the availability of bacterial culture results. When records did not indicate times for drug administration or discontinuation, midnight on the date indicated was assumed.

Descriptive analyses, Fisher's exact test, SEM, ANOVA and linear regressions were performed using SPSS (IBM Corporation, USA).

\section{RESULTS}

\section{Initial presentation}

The records of 34 EV-positive patients (nine adults, 25 children) and 83 control patients ( 57 adults, 26 children) were consulted for differences in signs, symptoms and characteristics using Fisher's exact test (Table 1). The EV-positive group was significantly younger (mean $[ \pm \mathrm{SD}] 7.9 \pm 2.0$ years) than the EV-negative group (mean $30.2 \pm 2.6$ years, $\mathrm{P}<0.001)$. There were no EV-positive patients older than 34 years of age.

Of the typical meningitis symptoms (headache, fever and stiff neck), most patients had a headache and did not have a stiff neck, regardless of their EV status. Fever was reported three times as often in the EV-positive group $(\mathrm{P}=0.002)$. EV-positive patients were almost three times more likely than EV-negative patients to have reported a rash $(35.3 \%$ versus $12.0 \%, \mathrm{P}=0.008)$ or photophobia (58.3\% versus $21.0 \%, \mathrm{P}=0.013)$. Patients with $\mathrm{EV}$ meningitis were also more likely to present within $48 \mathrm{~h}$ of onset $(78.6 \%$ versus $46.9 \%, \mathrm{P}=0.004)$ and to report an exposure to a sick contact ( $26.5 \%$ versus $9.8 \%, \mathrm{P}=0.040$ ).

EV-positive patients were less likely than EV-negative patients to report seizure $(2.9 \%$ versus $18.1 \%, \mathrm{P}=0.037)$ or to demonstrate focal neurological findings (6.3\% versus $36.1 \%, \mathrm{P}=0.001)$. However, the average Glasgow Coma Scores (GCS), where recorded, were near normal $(\mathrm{GCS}=15)$ and were statistically similar in both groups of patients. Recorded temperatures were significantly higher in EV-positive patients as calculated by $t$ test $\left(38.0 \pm 0.2^{\circ} \mathrm{C}\right.$ versus $37.2 \pm 0.1^{\circ} \mathrm{C}, \mathrm{P}<0.001$ ).

CSF findings demonstrated many similarities in both the pediatric and the adult populations (Table 2). All CSF glucose levels were within the normal range $(2.2 \mathrm{mmol} / \mathrm{L}$ to $3.9 \mathrm{mmol} / \mathrm{L})$, and all CSF protein levels were higher than normal $(0.15 \mathrm{~g} / \mathrm{L}$ to $0.45 \mathrm{~g} / \mathrm{L})$, with no significant differences within age groups. Mean CSF WBC counts were higher in the EV-positive adults. The proportion of mononuclear cells was similar in both those with and without EV infection, and in both children and adults.

PCR results for EV meningitis demonstrate a clear seasonality. Positive results were reported mainly between July and December ( $87.5 \%$ of yearly positive cases). September, October and November alone accounted for $60.4 \%$ of the yearly positive cases. The total number of EV PCR test requests also varied according to season $-65.3 \%$ of tests were ordered between July and December. Fisher's exact test demonstrated that the proportion of EV-positive patients of those tested between January and June was $4.88 \%$, while that of the period between July and December was $21.0 \%(\mathrm{P}=0.0003)$.

\section{The decision to admit}

In all, $83.6 \%$ of patients were admitted for treatment or observation $(\mathrm{n}=116$, one patient left against medical advice). A linear regression analysis was conducted on the following variables to determine the most important factors in patient admission: sex, age older than 16 years, headache, fever, stiff neck, rash, photophobia, onset of less than $48 \mathrm{~h}$, exposure to a sick person, the presence of seizure, focal neurological symptoms, GCS $<15$, nausea or vomiting, and 
TABLE 2

Cerebrospinal fluid (CSF) characteristics based on CSF enteroviral polymerase chain reaction test result

\begin{tabular}{|c|c|c|c|c|c|c|}
\hline \multirow[b]{2}{*}{ CSF characteristic } & \multicolumn{3}{|c|}{ Age $0-16$ years } & \multicolumn{3}{|c|}{ Age $>16$ years } \\
\hline & EV positive & EV negative & $\mathbf{P}$ & EV positive & EV negative & $\mathbf{P}$ \\
\hline Glucose, $\mathrm{mmol} / \mathrm{L}$ & $2.74 \pm 0.12(21)$ & $2.95 \pm 0.20(26)$ & 0.400 & $3.48 \pm 0.48(8)$ & $3.49 \pm 0.16(55)$ & 0.976 \\
\hline Protein, g/L & $1.02 \pm 0.20(21)$ & $1.57 \pm 0.63(26)$ & 0.453 & $0.63 \pm 0.09(8)$ & $0.89 \pm 0.07(55)$ & 0.157 \\
\hline Neutrophils, \% & $30.7 \pm 8.7(13)$ & $41.9 \pm 7.5(9)$ & 0.370 & $15.6 \pm 6.0(7)$ & $6.1 \pm 2.9(34)$ & 0.185 \\
\hline Mononuclear cells, \% & $65.5 \pm 9.0(13)$ & $50.9 \pm 9.3(9)$ & 0.287 & $84.1 \pm 6.0(7)$ & $91.38 \pm 3.6(34)$ & 0.390 \\
\hline
\end{tabular}

Data presented as mean \pm SEM (n), unless otherwise indicated. EV Enteroviral

TABLE 3

ANOVA of cerebrospinal fluid (CSF) characteristics based on admission status

\begin{tabular}{|c|c|c|c|c|c|c|}
\hline \multirow[b]{2}{*}{ CSF characteristic } & \multicolumn{3}{|c|}{ Age $0-16$ years } & \multicolumn{3}{|c|}{ Age >16 years } \\
\hline & Admitted & Not admitted & $\mathbf{P}$ & Admitted & Not admitted & $\mathbf{P}$ \\
\hline Glucose, mmol/L & $2.85 \pm 0.13(43)$ & $2.91 \pm 0.21(4)$ & 0.890 & $3.58 \pm 0.18(47)$ & $3.22 \pm 0.29(15)$ & 0.321 \\
\hline Protein, g/L & $1.41 \pm 0.39(43)$ & $0.43 \pm 0.09(4)$ & 0.448 & $0.86 \pm 0.08(47)$ & $0.82 \pm 0.11(15)$ & 0.798 \\
\hline White blood cell count, $10^{9} / \mathrm{L}$ & $220.72 \pm 103.89(47)$ & $21.25 \pm 12.26(4)$ & 0.581 & $177.70 \pm 53.71(47)$ & $330.00 \pm 129.54(15)$ & 0.208 \\
\hline Neutrophils, \% & $36.50 \pm 6.31(20)$ & $23.00 \pm 23.00(2)$ & 0.529 & $6.12 \pm 3.26(26)$ & $11.14 \pm 4.97(14)$ & 0.387 \\
\hline Mononuclear cells, \%) & $57.80 \pm 6.94(20)$ & $76.50 \pm 23.50(2)$ & 0.428 & $93.62 \pm 3.25(26)$ & $83.07 \pm 6.67(14)$ & 0.117 \\
\hline
\end{tabular}

Data presented as mean \pm SEM (n), unless otherwise indicated

confusion/loss of consciousness. The decision to admit was most influenced by: GCS $<15$ (11.6\% variance explained), focal neurological symptoms ( $8.3 \%$ variance explained) and the absence of photophobia (6.1\% of variance explained); accounting for a total of $26.0 \%$ of the variance seen between those admitted and those not admitted ( $n=59$, limited to the patients who had all characteristics recorded). Indeed, those who had a GCS $<15$ were always admitted to hospital $(14.13 \pm 0.23$ $[n=47$ ] versus $15.00 \pm 0.00$ in the nonadmitted group [ $n=15], P=0.040)$.

CSF properties, such as glucose or protein concentration, WBC count, or cell differential did not predict which patients would be admitted to the hospital (Table 3). Glucose levels were within the normal range $(2.2 \mathrm{mmol} / \mathrm{L}$ to $3.9 \mathrm{mmol} / \mathrm{L})$ in all patients. Children not admitted had a mean CSF protein level within the normal range $(0.15 \mathrm{~g} / \mathrm{L}$ to $0.45 \mathrm{~g} / \mathrm{L})$, whereas protein levels were elevated in admitted children and both admitted and discharged adults. The mean CSF WBC counts were elevated in all groups; however, nonadmitted children had a more modest WBC increase than the other groups. Fischer's exact test found no association between the proportion of patients admitted and the season in which they presented (September to November versus all other months, $\mathrm{P}=0.465$ ).

Of the 91 patients admitted to hospital (excluding five patients isolated for MRSA, and one patient who left against medical advice), $31(34.1 \%)$ were isolated before EV PCR test results. Linear regression, using factors specified above, demonstrated that children and those with rash were usually isolated, accounting for $26.3 \%$ and $9.1 \%$ of the variance, respectively. In the isolated group, the proportion who remained isolated following a positive EV PCR test (six of 15 [40.0\%]) was similar to the proportion of those with a negative EV PCR test (two of 16 [12.5\%], P=0.1134). Patients not presumptively isolated were placed on isolation when the EV PCR test was positive (five of $11[45.5 \%])$ more often than those whose EV PCR test was negative (two of $49[4.1 \%, \mathrm{P}=0.0015$ ) (Figure 1).

Patients admitted to hospital were subsequently found to be positive for EV in $27.83 \%$ of cases, and those discharged with no inpatient treatment were subsequently found to be EV-positive in $36.84 \%$ of cases $(\mathrm{P}=0.423)$.

The overall length of stay in hospital was shorter in the group whose CSF was positive for EV. The EV-positive group had a mean stay of $5.44 \pm 1.07$ days $(n=27)$, significantly fewer days than the EV-negative group $(14.31 \pm 2.36$ days $[n=70], P=0.024)$. A positive $E V$ PCR test result, however, did not significantly shorten the time between the test result and discharge (Table 4).
Anti-infective use

In all, 91 of $117(77.8 \%)$ patients were given at least one dose of a single anti-infective, although $16.67 \%$ received drugs for less than $24 \mathrm{~h}$ (where dates and times were available, $\mathrm{n}=89$ ). Of the 84 patients receiving empirical anti-infectives, $46(54.76 \%)$ received only antibiotics and seven $(8.33 \%)$ received only the antiviral acyclovir, while $31(36.90 \%)$ were prescribed both antibiotics and acyclovir. In all, 30 people $(33.7 \%, n=89)$ received their initial anti-infective dose before lumbar puncture. The mean age of those treated empirically was $18.68 \pm 2.48$ years, while the mean age of those not treated was $39.00 \pm 3.59$ years $(n=30, P<0.001)$. Age was not a factor in determining the administration of acyclovir specifically (data not shown).

Linear regression testing the patient characteristics mentioned above (see 'The decision to admit') revealed that patients were more likely to be treated empirically if they reported fever $(11.8 \%$ of variance explained) or had been ill for less than $48 \mathrm{~h}$ ( $8.1 \%$ of variance explained), explaining a total variance between the groups of $19.9 \%$. ANOVA of CSF properties suggested that no CSF characteristic influenced prescribing of empirical anti-infectives (data not shown).

Further analysis (linear regression using the same characteristics as above) of the empirically treated group demonstrated that age older than 16 years was a determinant in the provision of acyclovir, accounting for $22.6 \%(n=38)$ of the variability between the administered and the nonadministered groups. By linear regression, those receiving both antibiotics and acyclovir were also more likely to be adults. An age older than 16 years was responsible for $14.5 \%$ of the variance within the group who received both anti-infectives, headache for those receiving only acyclovir (20.6\% variance explained), and age older than 16 years and nausea $(22.6 \%$ and $10.0 \%$ variance, respectively) for those receiving antibiotics alone $(n=38)$. In the adult population, ANOVA demonstrated that a higher CSF glucose level was associated with acyclovir use $(\mathrm{P}=0.008, \mathrm{n}=37)$, while a lower CSF glucose level was associated with antibiotic use $(\mathrm{P}=0.015, \mathrm{n}=37)$. The presence of headache also played a role in the prescription of antibiotics, accounting for $20.6 \%$ of the variance between the treated group and the untreated group $(n=38)$, by linear regression.

Of all patients given anti-infectives (who also had a CSF Gram stain performed), $73.08 \%(\mathrm{n}=78)$ were still taking the drugs $24 \mathrm{~h}$ after the results of the Gram stain were reported. The proportion of patients still receiving anti-infectives $24 \mathrm{~h}$ after a bacterial culture result (for those who had their CSF cultured) was 35.96\% ( $n=89)$. Seven cultures revealed bacterial growth (several colonies or light 


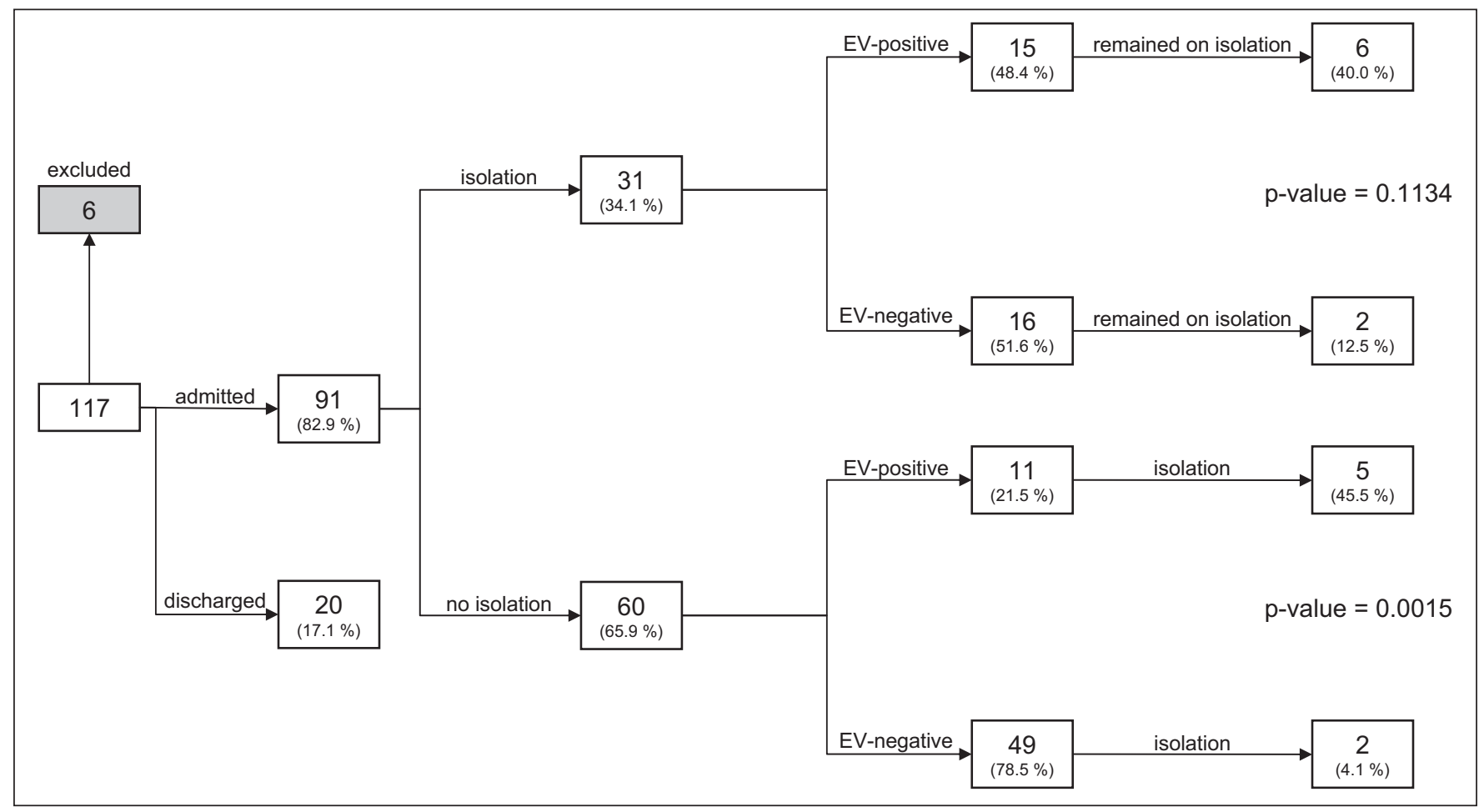

Figure 1) The empirical isolation of patients with suspected meningitis and response to receipt of enterovirus polmerase chain reaction test result. Excluded patients include one who left against medical advice, and five who were isolated because of a positive routine methicillin-resistant Staphylococcus aureus test. EV Enteroviral

\section{TABLE 4}

Experience in hospital based on CSF EV PCR test result

\begin{tabular}{lcrc}
\hline & \multicolumn{2}{c}{ EV PCR test result } & \multirow{2}{*}{ P } \\
\cline { 2 - 3 } & Positive & Negative & Pen \\
\hline Length of stay, days & $5.44 \pm 1.07(27)$ & $14.31 \pm 2.36(70)$ & 0.024 \\
PCR result to discharge, days & $2.45 \pm 0.74(27)$ & $8.73 \pm 2.04(66)$ & 0.055 \\
\hline
\end{tabular}

Data presented as mean \pm SEM (n) unless otherwise indicated. CSF

Cerebrospinal fluid; EV Enteroviral; PCR Polymerase chain reaction

growth of Staphylococcus species (five samples), and one case each of Moraxella osloensis and Escherichia coli). Twenty-four hours after a negative EV PCR test result, $41.38 \%(\mathrm{n}=58)$ of patients remained on anti-infectives, while that number was $25.81 \%(n=31)$ in those with a positive EV PCR test result $(\mathrm{P}=0.170)$. There was no evidence for an association between prelumbar puncture anti-infective administration and continuation of drug administration following a negative EV PCR test result (data not shown). Within the EV-positive group, eight $(36.36 \%, n=22)$ of those who were on antibiotics alone remained on the medications at least $24 \mathrm{~h}$ post-PCR result. Of those with a negative EV result who had received only antibiotics, $13(54.17 \%, \mathrm{n}=24)$ remained on those drugs at least $24 \mathrm{~h}$ after the results. One $(14.29 \%, \mathrm{n}=7)$ patient in the EV- negative group who received only acyclovir was still using acyclovir $24 \mathrm{~h}$ after the PCR test result.

\section{DISCUSSION}

There was a considerable overlap in the clinical and laboratory features of patients with and without EV meningitis. Patients with EV meningitis were frequently admitted and were treated empirically with antibiotics and acyclovir. EV meningitis was more common in younger patients and those with fever, rash, photophobia, sudden onset and a history of exposure to someone unwell. The prevalence of headache, fever, stiff neck and seizure are consistent with other studies of viral meningitis $(6,7)$. The oldest EV-positive patient in the present study was 34-years-old. Although statistically significant, the small difference in temperature $\left(0.8^{\circ} \mathrm{C}\right)$ is unlikely to be clinically useful. The higher rate of exposure to sick contacts in the EV-positive group may reflect the large pediatric representation (and therefore may include school/ daycare exposures or perhaps parents being over-inclusive in recalling sick person contacts).

CSF was generally not useful in differentiating patients with EV meningitis from those with other conditions. Although the median CSF WBC count was low in patients with EV meningitis, the upper end of the range was $2980 / \mathrm{mm}^{3}$. This WBC count is much higher than the WBC count of other reports of EV meningitis $(8,9)$ and is more consistent with bacterial meningitis $(10,11)$. As such, one can appreciate that a positive EV PCR test (virtually eliminating a bacterial cause from the differential diagnosis) should result in the discontinuation of antibiotics, although this was not clearly demonstrated in the present study.

We observed, as have others, that there is a marked seasonality of EV meningitis $(7,12)$. EV meningitis cases are rarely seen in the winter and spring $(2,12,13)$. Others have suggested that EV PCR testing of CSF can be performed routinely in infant patients during peak times resulting in reduced length of hospital stay and pharmaceutical use $(13,14)$. Interestingly, factors that seemed to lead to hospital admission (GCS $<15$, focal neurological findings and absence of photophobia) were characteristics of EV-negative patients. These data suggest an appropriate decision-making process, because EV-positive patients usually should not require hospitalization.

The difference in length of stay between the EV-positive and EV- negative patients was not surprising, because a positive result is very strong evidence for a self-limited disease. In spite of the clear association between a positive result and a shortened hospital stay, it is difficult to determine the extent to which a positive PCR test enabled clinicians to discharge the patient. Because EV meningitis is typically mild, many patients may have been promptly discharged by virtue of their improving clinical condition, had the test not been performed or had it been negative. Conversely, a negative EV PCR test may lead the physician to be tentative about releasing the patient, or the 
EV-negative patients may have had complicated illnesses that naturally led them to remain in hospital longer (EV-negative diagnoses in the present study included encephalitis, temporal lobe tumour, septicemia, seizure disorders, mononucleosis, central nervous system lymphoma, transient ischemic attack and others). EV PCR testing appeared to influence isolation precautions especially in patients who were previously not isolated.

The present study has several limitations. Due to its retrospective nature, we must rely on clinical notes that were recorded without the standards of a study design, sometimes resulting in missing data and, as with any such retrospective review, it is conceivable that some bias was introduced by using one individual to review and record all data. The retrospective nature of the review also limited us to the patients for whom we could gather information. Because there is no organized way to select all patients in the past three years exhibiting a set of symptoms, we used the performance of the EV PCR as a marker for those demonstrating meningitis symptoms. Before having the PCR test performed, however, the patient's characteristics must be such that their CSF is approved for testing by laboratory personnel. This means that there is a potential to miss patients whose CSF features or symptoms did not warrant the PCR test, making our findings more appropriately applied to the post-PCR test population, reducing the ability to generalize to all presenting patients. It is also therefore challenging to determine associations between samples that are rejected from testing and the symptoms, signs and seasonality. Although the PCR assay that we performed was developed in house, it is unlikely that the performance characteristics of a commercial assay would be different enough to affect the gerneralizability of our findings.

Adult patients who received antibiotics were likely to have relatively low glucose levels, a sign associated with bacterial meningitis (10). Surprisingly, one-fourth of patients who were empirically treated

\section{REFERENCES}

1. Ziai WC, Lewin JJ III. Update in the diagnosis and management of central nervous system infections. Neurol Clin 2008;26:427-68.

2. Irani DN. Aseptic meningitis and viral myelitis. Neurol Clin 2008;26:635-55.

3. Sawyer MH. Enterovirus infections: Diagnosis and treatment. Pediatr Infect Dis J 1999;18:1033-40.

4. Hamilton MS, Jackson MA, Abel D. Clinical utility of polymerase chain reaction testing to enteroviral meningitis.

Pediatr Infect Dis J 1999;18:533-7.

5. Marshall GS, Hauck MA Buckland G, Rabalais GP. Potential cost savings through rapid diagnosis of enteroviral meningitis. Pediatr Infect Dis J 1997;16:1086-7.

6. Chadwick DR, Lever AML. The impact of new diagnostic methodologies in the management of meningitis in adults at a teaching hospital. Q J Med 2002;95:663-70.

7. Tavakoli NP, Wang H, Nattanmai S, Dupuis M, Fusco H, Hull R. Detection and typing of enteroviruses from CSF specimens from patients diagnosed with meningitis/encephalitis. J Clin Virol 2008;43:207-11.

8. Baty V, Viel J-F, Schuhmacher H, Jaeger F, Canton B, B Hoen. Prospective validation of a diagnosis model as an aid to therapeutic decision-making in acute meningitis.

Eur J Clin Microbiol Infect Dis 2000;19:422-6. remained on the anti-infectives after the positive PCR test result was available. This proportion was not significantly different than that of patients who were negative for EV, suggesting that the EV PCR test result did not impact anti-infective use in aseptic meningitis. More than one-third of EV-positive patients who were given only antibiotics remained on the drugs $24 \mathrm{~h}$ post-result. Clearly, this use of antibiotics is inappropriate, because a positive EV result essentially eliminates the possibility of a bacterial cause.

Our study presents Canadian data and, as such, reflects a Canadian experience. The present study further highlights the inhernet difficulty in differentiating patients with and without EV meningitis on clinical and laboratory characteristics although several features are predictive. We observed that it is rare for an EV-positive patient to present with focal neurological symptoms or with seizures. EV meningitis did not occur beyond 40 years of age nor was it common in the winter or spring. The present study suggests that EV PCR testing can be forgone in populations that are likely to yield a negative result (based on age or seasonality), thereby saving resources and concentrating efforts elsewhere. We also provide evidence that a positive EV PCR test results in decreased hospitalization, thereby reducing associated costs and risks to the patient. Taken together, these findings suggest that EV meningitis management can be made more efficient by restricting testing to appropriate populations (reducing low-yield tests) and confirming an EV etiology, thereby allowing for a safe and prompt discharge.

ACKNOWLEDGEMENTS: This work was funded by a studentship to GP from the Webster Summer Studentship for Research in Immunology and Genetics. Josh Gould provided statistics assistance. Dr Tim Mailman facilitated the review of the paediatric medical records.

9. Archimbaud C, Chambon M, Bailly JL et al. Impact of rapid enterovirus molecular diagnosis on the management of infants, children, and adults with aseptic meningitis. J Med Virol 2009;81:42-8.

10. Hoen B, Viel JE, Paquot C, Gerard A, Canton P. Multivariate approach to differential diagnosis of acute meningitis. Eur J Clin Microbiol Infect Dis 1995;14:267-74.

11. Zarrouk V, Vassor I, Bert F, et al. Evaluation of the management of postoperative aseptic meningitis. Clin Infect Dis 2007;44:1555-9.

12. Stellrecht KA, Harding I, Woron AM, Lepow ML, Venezia RA. The impact of an enteroviral RT-PCR assay on the diagnosis of aseptic meningitis and patient management. J Clin Virol 2002;25:S19-S26.

13. Nigrovic LE, Chiang VW. Cost analysis of enteroviral polymerase chain reaction in infants with fever and cerebrospinal fluid pleocytosis. Arch Pediatr Adolesc Med 2000;154:817-21.

14. King RL, Lorch SA, Cohen DM, Hodinka RL, Cohn KA, Shah SS. Routine cerebrospinal fluid enterovirus polymerase chain reaction testing reduces hospitalization and antibiotic use for infants 90 days of age or younger. Pediatrics 2007;120:489-96. 


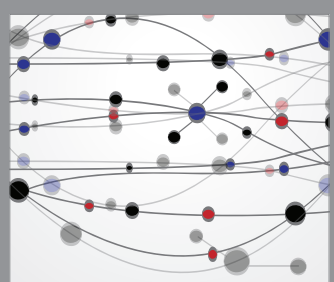

The Scientific World Journal
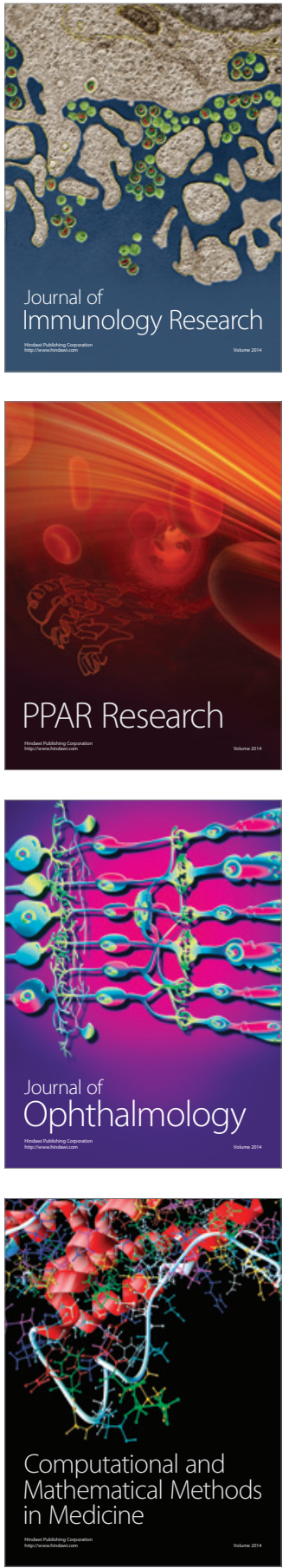

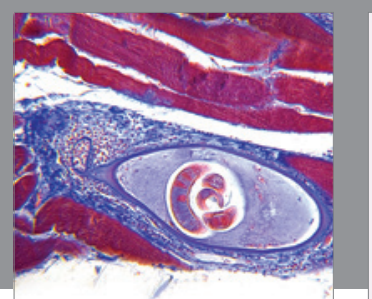

Gastroenterology Research and Practice

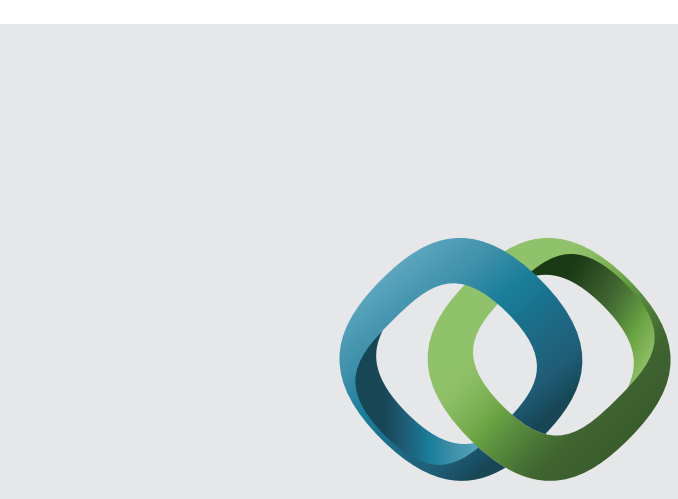

\section{Hindawi}

Submit your manuscripts at

http://www.hindawi.com
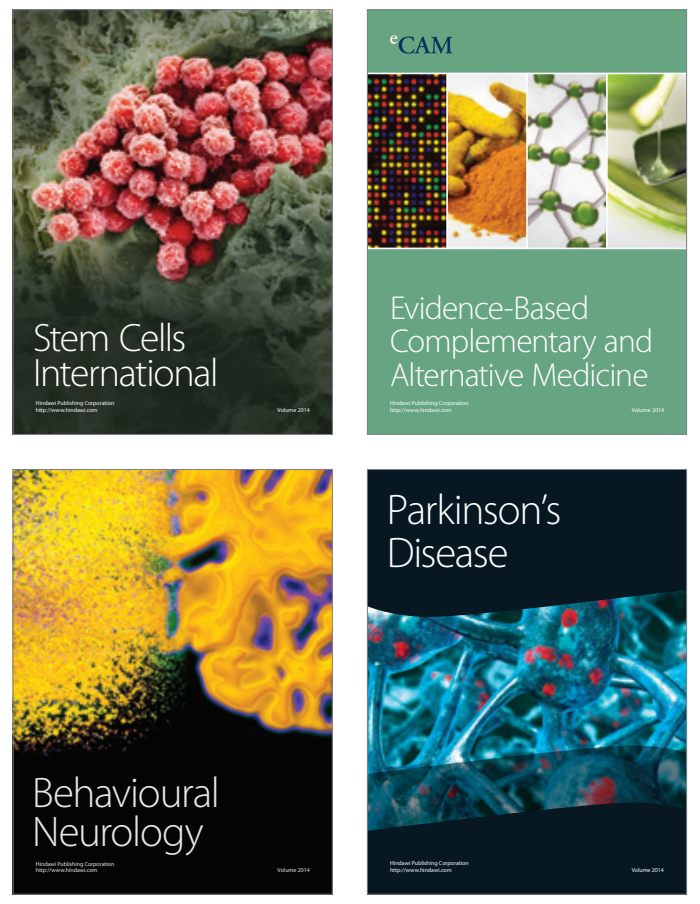
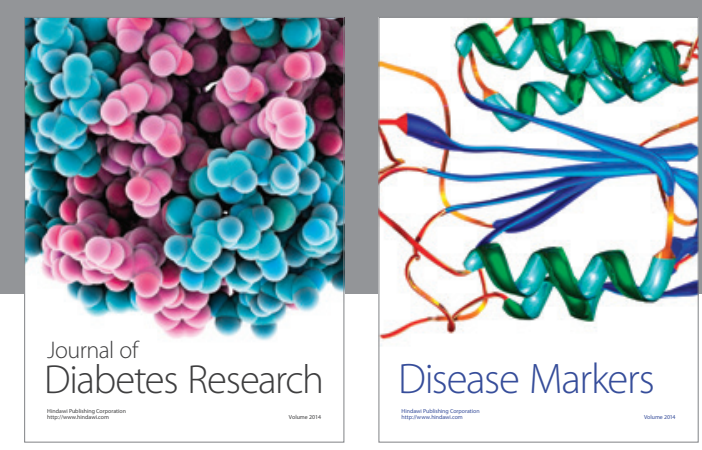

Disease Markers
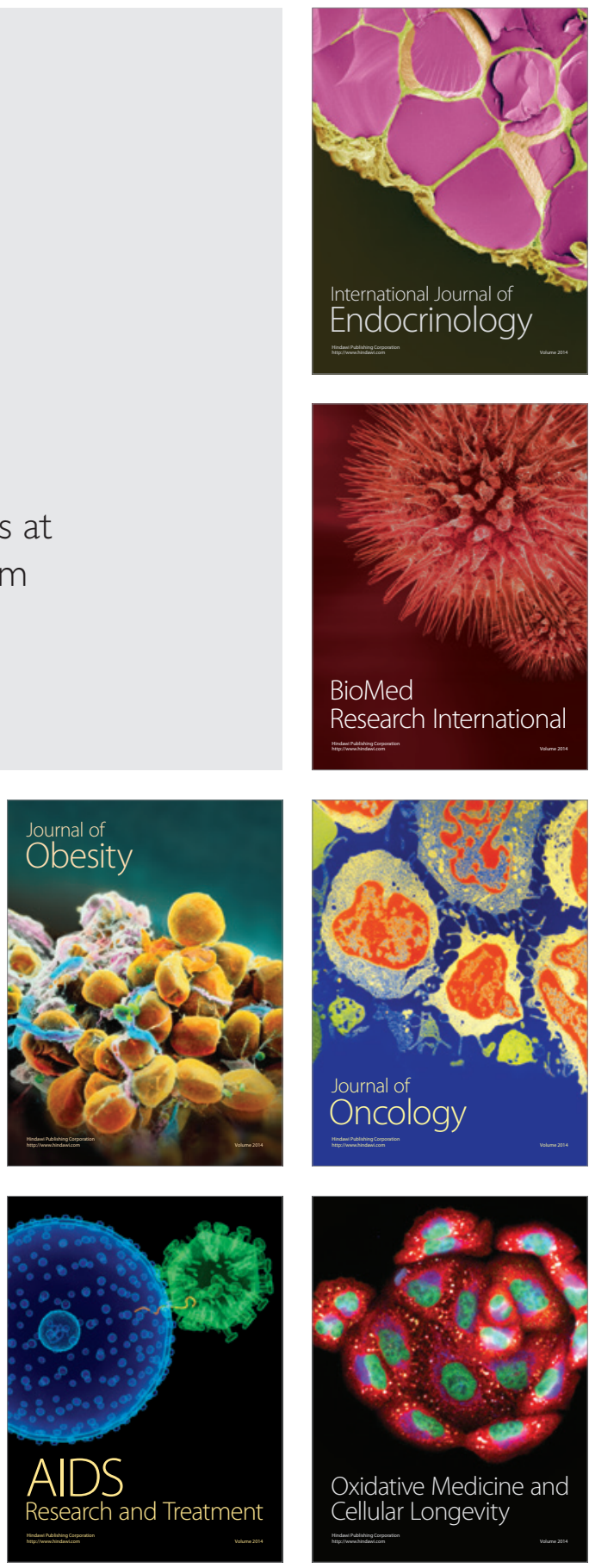